\title{
An Analysis of Grammatical Items in High School English Textbooks and A Correlation Analysis Between English Textbooks and the Grammatical Test Items of CSAT
}

\author{
Ji-Hye $\mathrm{Im}^{1)}$, Mun-Koo Kang ${ }^{2)}$, Hyung-Ji Chang ${ }^{3)}$
}

\author{
고등학교 영어 교과서에 제시된 문법요소들의 분석과 \\ 대학수학능력시험 어법 문항과의 상관관계 분석$$
\text { 임지혜1), 강문구2), 장형지3) }
$$

\begin{abstract}
The aim of this study is to analyze the grammatical items in the High School English I and II textbooks in Korea and compare them with the grammar test items of College Scholastic Ability Test (CSAT). To achieve this goal, this study analyzed grammatical items in high school English textbooks which follow the revised 2015 National Curriculum of Korea. Also, the grammatical test items of CSAT from 2016 to 2020 were analyzed. The results of this study are as follows : 1) More different categories of grammar items are shown in High School English II textbooks rather than High School English I textbooks. 'Participle' shows the highest frequency in High School English I whereas 'adverbial clauses' are presented the most frequently in High School English $\Pi$. 2) The results of correlation analysis on the frequencies of grammatical items between High School English I textbooks and CSAT and between High School English $\amalg$ textbooks and CSAT are insignificantly recognized.
\end{abstract}

Keywords: High School English Textbooks, Grammatical items, CSAT, Correlation Analysis

$$
\text { 요 약 }
$$

이 연구의 목적은 2015 개정 고등학교 교과서 영어 I 과 영엎ㅇ 문법요소를 분석하고 그 결과를

Received(June 25, 2020), Review Result(1st: August 19, 2020, 2nd: October 3, 2020), Accepted(October 28, 2020)

1) (Ph.D Course Student) 32588 Kongju National University, 56 Gongjudaehak-ro, Gongju-si, Chungnam-do, South Korea

email: jihye3633@naver.com

2) (Professor, Corresponding Author) 32588 Dept. of English Education, Kongju National University, 56 Gongjudaehak-ro, Gongju-si, Chungnam-do, South Korea

email: kangmunkoo@hanmail.net

3) (Professor) 31460 Dept. Global Tourism, Sun Moon Univ., Asan, South Korea

email: maria5576@hanmail.net 


\section{An Analysis Of Grammatical Items In High School English Textbooks And A Correlation Analysis Between Engtish Textbooks And The Grammatical Test Items Of CSAT}

대학수학능력시험 외국어 영역의 어법 문항과 상관관계 분석하는 것이다. 2015 개정 고등학교 교과서 영어 I 과 영어 II에 있는 단원별 핵심 언어형식에 포함된 문법요소들을 대상으로 빈도 분석을 시행 하였다. 또한 2016년부터 2020년까지 대학수학능력시험의 어법 문항을 분석하였다. 이 연구의 결과는 다음과 같다. 첫째, 검인정 교과서 간에 공통된 핵심 문법요소들은 영어 I 이 영엎ㅂ보다 더 많았고, 영어 $\Pi$ 는 교과서마다 다양한 종류의 문법요소들을 다루어 상대적으로 교과서마다 공통된 문법요소들 이 적었다. 영어 I 교과서에서는 '분사구문' 관련 요소가 한 교과서 내서도 중복적으로 다뤄지며 가장 많이 출현한 것에 반해 영어표교과서에서는 ‘부사절' 관련 요소들이 가장 빈번하게 출현하였다. 둘째, 영어 I 과 영어 II 교과서의 문법요소를 분석한 결과와 대학수학능력시험 어법 문항의 문법요소와 상관관계를 분석한 결과 통계적으로 유의미하지는 않았지만 낮은 상관관계를 보였다.

핵심어: 고등학교 영어 교과서, 문법요소, 대학수학능력시험 어법 문항, 상관관계 분석

\section{1. 서론}

한국의 영어 교육은 다양하게 변화해왔으며 현재는 의사소통 능력을 기르기 위한 여러 교수 방법 들이 있다. 한때, 학습자들의 영어 노출 시간이 부족하다는 이유로 영어를 사용해 다른 과목을 배 우는 몰입교육이 등장하기도 했었다[1]. 2015 개정 영어과 교육과정의 세부목표에서는 “학습자들이 중학교에서 배운 영어를 토대로 일반적인 주제에 관한 영어를 이해하고 표현하여 의사소통 능력을 심화 및 발전시켜 나아가는 것"[2] 이라고 명시하며 의사소통 능력에 대해 강조하였다. 하지만 과 거의 문법 중심적인 교육에 대한 반발로 문법 교육에 대해 부정적인 시선이 만연했으며 2015 개정 영어과 교육과정의 교수.학습 및 평가 유의사항[2]에는 문법 교육의 목표 혹은 가이드 없이 학교급 에 따른 언어형식과 예문만이 부록으로 첨가되어있다. 교과서에도 용어의 사용이나 명시적인 문법 학습보다는 본문 속에서 1 2개 정도의 예문을 제시하는 정도로 교사와 학습자가 문법 학습의 필 요성을 느끼기 힘들다.

우리나라는 일상생활에서 영어를 공용으로 사용하지 않는 $\mathrm{EFL}$ 상황으로 일상대화보다는 텍스트 를 통한 언어의 습득과 표현이 더 많이 이루어지고 있다. 실제로 문법 지식은 정확한 독해를 하는 데 필수적인 요건이지만 교실 안팎에서 문법에 대한 수업이나 평가가 표면적으로 이루어지지 않기 때문에 교사들이나 학생들이 문법학습을 경시할 우려가 있다. 이지혜와 강문구(2017)는 언어학습의 'Four skills'를 조화롭게 발전시키기 어려운 이유 중 하나는 문법학습의 부족이라고 언급했다[3]. 또한 권연아와 강문구(2016)는 검인정 교과서는 한국 공교육의 주요 특징이며, 학생들은 교과서로 부터 영어교육에 필요한 언어적 입력을 받기 때문에 교과서가 어떻게 조직되느냐가 학습 성패에 중요한 역할을 한다고 하였다[4]. 이러한 측면에서 볼 때 언어형식과 문법 지식에 관한 교육은 학 교에서 이루어져야 하며 교과서는 학습자들이 문법 자료를 접하고 학습을 할 수 있는 주요 학습 도구로써 매우 중요하다. 또한 교과서와 대학수학능력시험과의 연관성도 중요하다. 사교육비 경감 정책의 일환으로 EBS 교재를 수능과 연계한 이후 일선 고등학교 수업에서는 교과서가 아닌 EBS 교재를 사용한 문제 풀이 수업이 이루어지고 있다. 이로 인해 학생들이 학교 수업에서 교과서의 필요성에 대해서 의문을 가질 뿐만 아니라 교과서 자체에 대한 신뢰도 또한 낮아지고 있다. 따라 서 교과서와 대학수학능력시험과의 상관 정도를 분석하는 연구는 대학수학능력시험 문항 제작에 
참고자료로 쓰일 수 있을 것이다. 출제자들이 각 교과서에 나오는 언어형식의 종류와 분포를 파악 하여 문항 제작에 반영한다면 교과서와 대학수학능력시험과의 연관성은 더 높아질 것이다. 이는 학생들에게 교과서에 대한 신뢰도를 높이고 학교 수업도구로써의 역할을 충분히 할 수 있도록 할 것이다. 이러한 이유로 교과서와 대학수학능력시험의 문법 문항의 비교연구는 필수적이다. 따라서 본 연구에서는 2015 개정 교육과정 고등학교 영어 교과서에서 제시된 언어형식에 나타난 문법요소 의 종류와 빈도를 분석하고 이 문법 요소가 최근 5 년간의 대학수학능력시험의 어법 문제와 어느 정도의 연관성이 있는지 상관관계 분석을 해 보려고 한다. 따라서 다음과 같은 연구 문제를 설정 하였다.

1) 2015 개정 교육과정 고등학교 교과서 영어| 과 영어॥의 단원별 언어 형식에 나타난 문법요 소의 종류와 비율은 어떠한가?

2) 각 교과서의 문법요소들과 최근 5 개년도의 대학수학능력시험의 어법 문항은 어느 정도의 상 관관계가 있는가?

\section{2. 이론적 배경}

\section{1 문법 교육}

문법(Grammar)에 대해서 많은 학자는 다양하게 정의를 내리고 있다. Celce-Murcia와 Larsen-Freeman(2015)은 '... it is a set of rules that describes the structure of sentences or parts of them.'이라며 문법은 문장의 구조 혹은 그 부분을 서술하는 일련의 규칙이라는 문법의 일반적 인 정의를 소개하였다[5]. 영문법의 세부적인 용법과 사용이 연구되는 가운데[3][6] 이를 학습자에 게 전달하고 적용할 수 있게 하는 방법도 중요해졌다. 하지만 영어교육에서 지나친 문법 중심의 교수 방법이 비판을 받았고 뒤이어 의미를 중점으로 하는 교수 방법도 언어의 정확성을 간과했다 는 평가를 받았다. 그 후 등장한 Long(1991)의 형태초점의사소통접근법(Focus on Form Approach)[7] 은 의미와 의사소통으로 이루어진 수업 중 필요에 따라 학습자의 주의를 형태에 집중시키며, 의사 소통 중심 수업 안에서 적절하게 언어형식에도 초점을 맞추도록 했다.

\section{2 교과서와 대학수학능력평가시험 대상 연구}

대학수학능력시험과 교과서 문법요소와의 연관성을 분석한 연구는 많지 않다. 그중 구현정과 박은 수(2013)는 고등학교 영어 교과서 문법 분석 및 대학수학능력시험 문법 문항과의 연계성 연구를 통해 교과서와 대학수학능력시험에서 강조하고 있는 문법 사항이 서로 다르다는 결과를 얻었으며 고등학교 교과서에 제시되고 있는 문법 항목들이 대학수학능력시험과 연계되어 영어 교과서와 학 교 교육과정이 충분한 신뢰성을 확보해야 한다고 언급하였다[8]. 김지해, 김해동(2015)은 영어 | 교 과서 내의 문법 요소와 5 개년 동안 시행된 대학수학능력시험 영어 문법 문항의 문법 요소 간의 빈 도에 따른 상관관계를 측정한 결과 낮은 연계성을 보였다. 또한 학습자와 교사들은 교과서가 대 
An Analysis Of Grammatical Items In High School English Textbooks And A Correlation Analysis Between English Textbooks And The Grammatical Test Items Of CSAT

수능의 문법 문항을 준비하는 데 도움이 되지만 다른 참고서가 필요하다는 점에 공감하며, 교과서 내 문법 학습에 대한 유용도와 흥미도에 대해서는 부정적인 반응을 보였다고 한다[9].

\section{3. 연구 방법}

\section{1 연구절차}

본 연구는 2015 개정 교육과정 고등학교 영어 교과서에 제시된 문법 요소와 대학수학능력시험 어 법 문항 간의 상관관계를 분석한 연구로 그 절차를 요약하면 다음과 같다.

1) 영어|과 영어||에 제시된 세부 문법요소의 종류와 빈도를 파악하고 관련이 있는 요소들을 범위가 큰 문법 범주로 모아 백분율로 환산하여 전체 문법 간의 비율을 확인한다.

2) 각 교과서와 대학수학능력시험의 어법 문항의 문법요소 간의 상관계수 분석을 하여 연관성을 파악한다.

\section{2 분석대상}

\subsection{1 영어 교과서}

분석 대상은 2015 개정 검인정 고등학교 영어 교과서 영어 | 의 총 10 종과 영어 II 의 총 9종 교과서 이다. 한국교육과정평가원(2019)의 2020학년도 대학수학능력시험 시행 기본계획[10]에 따르면 수능 외국어 영역은 고등학교 교육과정에 제시된 영어 교과의 영어I, 영어II 과목을 바탕으로 다양한 소재의 지문과 자료를 활용하여 출제한다고 하였다. 고등학교 교육과정에서 2015 개정 교육과정은 2018년도에 적용되었지만, 기존 수능에 출제된 어법이 새로운 교육과정에 적절히 반영되었는지의 여부를 포함한 연관성을 살펴볼 수 있도록 2015 개정 검인정 고등학교 영어 | 와 영어॥를 분석대 상으로 선택하였다. 다음의 [표 1]과 [표 2]는 영어 교과서의 출판사명을 가나다순으로 정렬한 표이 다.

[표 1] 2015 개정 검인정 고등학교 영어 I 교과서

[Table 1] High School English I Textbooks Which Follow The Revised 2015 National Curriculum of Korea

\begin{tabular}{|c|c|c|c|}
\hline 번 호 & 출 판 사 & 교 재 명 & 저 자 \\
\hline 1 & 교학사 & High School English I [11] & 강문구 외 7인 \\
\hline 2 & 금성출판사 & High School English I [12] & 최인철 외 8인 \\
\hline 3 & 다락원 & High School English I [13] & 김길중 외 6인 \\
\hline 4 & 동아출판 & High School English I [14] & 권혁승 외 5인 \\
\hline 5 & 비상교육 & High School English I [15] & 홍민표 외 7인 \\
\hline 6 & 엔이능률 & High School English I [16] & 김성곤 외 8인 \\
\hline 7 & 와이비엠 & High School English I [17] & 박준언 외 6인 \\
\hline
\end{tabular}




\begin{tabular}{|c|c|c|c|}
\hline 8 & 와이비엠홀딩스 & High School English I [18] & 한상호 외 5인 \\
\hline 9 & 지학사 & High School English I [19] & 민찬규 외 7인 \\
\hline 10 & 천재교육 & High School English I [20] & 이재영 외 6인 \\
\hline
\end{tabular}

[표 2] 2015 개정 검인정 고등학교 영어표교과서

[Table 2] High School English $\amalg$ Textbooks Which Follow The Revised 2015 National Curriculum of Korea

\begin{tabular}{|c|c|c|c|}
\hline 번 호 & 출 판 사 & 교 재 명 & 저 자 \\
\hline 1 & 금성출판사 & High School English П[21] & 최인철 외 7인 \\
\hline 2 & 다락원 & High School English П[22] & 김길중 외 6 인 \\
\hline 3 & 동아출판 & High School English П[23] & 권혁승 외 5 인 \\
\hline 4 & 비상교육 & High School English П[24] & 홍민표 외 4인 \\
\hline 5 & 엔이능률 & High School English П[25] & 김성곤 외 6 인 \\
\hline 6 & 와이비엠 & High School English П[26] & 박준언 외 6 인 \\
\hline 7 & 와이비엠홀딩스 & High School English П[27] & 한상호 외 5인 \\
\hline 8 & 지학사 & High School English П[28] & 민찬규 외 7인 \\
\hline 9 & 천재교육 & High School English П[29] & 이재영 외 6인 \\
\hline
\end{tabular}

\subsection{2 대학수학능력시험 어법 문항}

대학수학능력시험에서 어법 문항은 2014년부터 1문항으로 유지되고 있고 5개의 보기를 포함하고 있다. 어법 문항은 단순한 암기를 해야 하는 문법 지식을 평가하는 것도 있지만, 밑줄 친 부분이 전체 글의 맥락 속에서 문법적으로 정확하게 표현되었는지 파악하는 능력을 평가하고 있다. 따라 서 글의 전반적인 내용 이해를 위한 독해력과 정확한 표현을 추려낼 수 있는 정확한 문법적 지식 이 필요하다. 대학수학능력시험에서 글의 내용 이해를 포함한 독해력이 주요하게 평가되고 있는 가운데 학습자들은 문법 학습을 할 기회가 상대적으로 줄고, 주로 교과서를 통해 문법 지식을 습 득할 수 있다. 따라서 1 문항으로 낮은 비율을 차지하지만, 문법 지식을 평가하고 있는 어법 문항의 문법 요소와 교과서의 연관성은 중요하기 때문에 이를 분석대상으로 선택하였다.

\section{3 분석 방법}

본 연구의 문법요소 분류기준은 2015 교육과정에서 제시된 40 개의 문법 항목의 기준과는 다르며 교과서와 대학수학능력시험 영어 문항의 선택지들을 대상으로 분류기준을 정하고 문법요소의 빈도 를 조사하여 결과를 정량화하였다. 본 연구에서 문법 요소를 추출하기 위해 정수영(2017)[30]이 제 시한 아래의 기준을 따랐다.

1) 쉬운 어구, 절 수준의 '형태소'에 관한 것으로, '동사의 시제', '양화사', '고유명사'와 같이 쉽 
An Analysis Of Grammatical Items In High School English Textbooks And A Correlation Analysis Between English Textbooks And The Grammatical Test Items Of CSAT

게 문법 용어로 설명될 수 있는 형태소적인 문법요소를 포함한다.

2) 복잡한 단위의 문형 구조를 가지고 '구문형식'의 상대적으로 복잡한 문법요소를 포함한다. 예 시로 'It istthat -', '상관접속사 neither A nor B' 등과 같이 예시문을 포함하여 설명되는 문장형 문법요소를 포함한다(정수영, 2017)[30].

\section{4. 연구결과}

분석에 사용된 영어 I, 10 종의 분석 대상 교과서에서 제시한 언어형식은 총 120 개로 나타났고 이것 들은 굉장히 세부적인 문법요소로 구문이나 표현에 가깝다. 따라서 같은 문법 항목을 다루더라도 교 과서마다 다른 핵심 요소들이 제시되어 있었다. 이를 고려하여 여러 교과서에 걸친 문법요소 중 중 복되는 내용을 제외하고 관련 문법요소들을 큰 범주로 모아 각 요소 간의 비율을 분석하였다.

[표 3] 2015 개정 영어 I 교과서 전체 문법요소 비율

[Table 3] The Percentage Of Grammatical items in High School English I Textbooks Which Follow The Revised 2015 National Curriculum of Korea

\begin{tabular}{|c|c|c|c|c|c|c|c|}
\hline 번 호 & 문 법 요 소 & 빈도수 & 백분율 & 번 호 & 문 법 요 소 & 빈도수 & 백분율 \\
\hline 1 & 분사 & 15 & $12.50 \%$ & 17 & 수일치 & 2 & $1.67 \%$ \\
\hline 2 & 관계대명사 & 14 & $11.67 \%$ & 18 & 요구·주장·제안 동사 & 2 & $1.67 \%$ \\
\hline 3 & 부사절 & 11 & $9.17 \%$ & 19 & 동등비교 & 2 & $1.67 \%$ \\
\hline 4 & 문두강조표현 & 9 & $7.50 \%$ & 20 & 재귀대명사 & 2 & $1.67 \%$ \\
\hline 5 & 부정사 & 9 & $7.50 \%$ & 21 & 전치사+ing & 2 & $1.67 \%$ \\
\hline 6 & 가정법 & 8 & $6.67 \%$ & 22 & 조동사 & 2 & $1.67 \%$ \\
\hline 7 & 관계부사 & 5 & $4.17 \%$ & 23 & in doing so & 1 & $0.83 \%$ \\
\hline 8 & 수동태 & 5 & $4.17 \%$ & 24 & $\begin{array}{c}\text { It goes without } \\
\text { saying that 주어+동사 }\end{array}$ & 1 & $0.83 \%$ \\
\hline 9 & it that/who 강조구문 & 4 & $3.33 \%$ & 25 & the same as 구문 & 1 & $0.83 \%$ \\
\hline 10 & 복합관계사 & 4 & $3.33 \%$ & 26 & 간접화법 & 1 & $0.83 \%$ \\
\hline 11 & one of 복수명사구문 & 3 & $2.50 \%$ & 27 & 과거완료 & 1 & $0.83 \%$ \\
\hline 12 & $\begin{array}{c}\text { 명사절 } \\
\text { (what, if, whether) }\end{array}$ & 3 & $2.50 \%$ & 28 & 동격(of, that) & 1 & $0.83 \%$ \\
\hline 13 & 의문문 & 3 & $2.50 \%$ & 29 & 동명사 & 1 & $0.83 \%$ \\
\hline 14 & to one's 감정명사 & 2 & $1.67 \%$ & 30 & 부분부정 & 1 & $0.83 \%$ \\
\hline 15 & 대동사 do & 2 & $1.67 \%$ & 31 & 형용사, 관사 & 1 & $0.83 \%$ \\
\hline 16 & 비교급 & 2 & $1.67 \%$ & & & & \\
\hline
\end{tabular}

전체 문법 항목 가운데 분사구문 관련 요소가 15 개로 가장 많았으며 전체 비율에서 $12.5 \%$ 를 차 지하였다. 다음으로는 관계대명사 관련 요소가 14 개로 $11.67 \%$ 의 비율을 차지하였으며 부사절 관련 


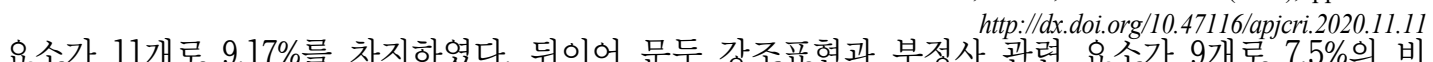
율을 차지하였고 가정법은 8 개로 $6.67 \%$ 의 비율을 차지하였으며 관계부사와 수동태 관련 요소는 각 각 5 개로 $4.17 \%$ 의 비율을 나타내고 있다. it that/who 강조구문, 복합관계사는 4 회로 $3.33 \%$ 의 비율을 나타내었고, one of 복수 명사 구문, 명사절, 의문문은 3회, $2.5 \%$ 의 비율을 차지하였다. 2회 씩 출현한 to one's 감정 명사 외 8 개 항목은 각각 $1.67 \%$ 의 비율을 보였으며, in doing so 구문 외 8 개 항목은 1 회 출현으로 각각 $0.83 \%$ 의 비율을 차지하였다.

총 9종의 2015 개정 영어 II 교과서에 제시된 언어형식은 총 106 가지이며 이것 역시 중복되는 내용을 제외하고 범주가 큰 항목으로 모아 각각의 문법요소 간의 비율을 분석하였다.

[표 4] 2015 개정 영엎ㄱㄱ과서 전체문법 요소 비율

[Table 4] The Percentage Of Grammatical items in High School English II Textbooks Which Follow The Revised 2015 National Curriculum of Korea.

\begin{tabular}{|c|c|c|c||c|c|c|c|}
\hline 번 호 & 문 법 요 소 & 빈도수 & 백분율 & 번 호 & 문 법 요 소 & 빈도수 & 백분율 \\
\hline 1 & 부사절 & 9 & $8.49 \%$ & 17 & 관계부사 & 2 & $1.89 \%$ \\
\hline 2 & 가정법 & 8 & $7.55 \%$ & 18 & 동격의of/that & 2 & $1.89 \%$ \\
\hline 3 & 분사 & 8 & $7.55 \%$ & 19 & 상관접속사 & 2 & $1.89 \%$ \\
\hline 4 & 동명사 & 7 & $6.60 \%$ & 20 & 동등비교 & 2 & $1.89 \%$ \\
\hline 5 & to 부정사 & 7 & $6.60 \%$ & 21 & 비교급 & 2 & $1.89 \%$ \\
\hline 6 & 수동태 & 7 & $6.60 \%$ & 22 & 재귀대명사 & 2 & $1.89 \%$ \\
\hline 7 & 명사절 & 6 & $5.66 \%$ & 23 & $\begin{array}{r}5 \text { 형식문장의 } \\
\text { 목적격보어 }\end{array}$ & 1 & $0.94 \%$ \\
\hline 8 & 시제 & 6 & $5.66 \%$ & 24 & it that/who강조구문 & 1 & $0.94 \%$ \\
\hline 9 & 조동사 & 5 & $4.72 \%$ & 25 & never too to구문 & 1 & $0.94 \%$ \\
\hline 10 & 병렬구조 & 4 & $3.77 \%$ & 26 & a(n)+형용사+명사+tha & 1 & $0.94 \%$ \\
\hline 11 & not A but $\mathrm{B}$ & 3 & $2.83 \%$ & 27 & 감각동사+형용사 & 1 & $0.94 \%$ \\
\hline 12 & 관계대명사 & 3 & $2.83 \%$ & 28 & 독립부사구 & 1 & $0.94 \%$ \\
\hline 13 & 문두강조표현 & 3 & $2.83 \%$ & 29 & 물주 구문 & 1 & $0.94 \%$ \\
\hline 14 & 복합관계사 & 3 & $2.83 \%$ & 30 & 이어 동사 & 1 & $0.94 \%$ \\
\hline 15 & 요구·주장·제안동사 & 3 & $2.83 \%$ & 31 & $\begin{array}{r}\text { 전치사 to와 to부정사 } \\
\text { 구분하기 }\end{array}$ & 1 & $0.94 \%$ \\
\hline 16 & cannot enough & 2 & $1.89 \%$ & 32 & 화법 & 1 & $0.94 \%$ \\
\hline
\end{tabular}

영어 II 교과서에 부사절 관련 문법요소들은 총 9 개로 $8.49 \%$ 를 차지하였으며, 가정법과 분사구문 관련 문법요소는 8 개로 $7.55 \%$ 의 비율을 차지하였고, 동명사, to 부정사, 수동태 관련 문법요소들은 각각 7 개로 $6.6 \%$ 의 비율을 차지하였다. 명사절과 시제 관련 문법들은 6 개로 $5.66 \%$ 의 비율을 보였으 
An Analysis Of Grammatical Items In High School English Textbooks And A Correlation Analysis Between English Textbooks And The Grammatical Test Items Of CSAT

며, 조동사 관련 문법들은 5 개로 $4.72 \%$ 의 비율을 보였다. 병렬구조는 4 회 출현으로 $3.77 \%$ 를 나타냈 고, 3회 출현한 not A but B 구문, 관계대명사, 문두 강조표현, 복합관계사, 요구·주장-제안 동사 는 각각 $2.83 \%$ 의 비율을 보였다. cannot enough 구문 외 6 개 항목은 2회 출현하여 각각 $1.89 \%$ 의 비율을 차지하였고, 5 형식 문장의 목적격 보어 외 9 개 요소는 1 회 출현으로 각 $0.94 \%$ 의 비율을 차 지했다.

지난 5 년간의 대학수학능력시험 출제된 어법 문항은 5 개이며 출제된 문법 내용은 25 가지로 중복 된 것을 제외하면 14 개 요소이다.

[표 5] 2016년부터 2020년까지의 대학수학능력시험 어법 문항 분석

[Table 5] An Analysis Of Grammatical Items In CSAT From 2016 To 2020

\begin{tabular}{|c|c|c|c|c|c|c|c|c|}
\hline 번 호 & 문 법 요 소 & 2016 & 2017 & 2018 & 2019 & 2020 & 합 계 & 비 율 \\
\hline 1 & 대명사 & 1 & 1 & 1 & 1 & & 4 & $16.00 \%$ \\
\hline 2 & 명사절 & 1 & 1 & 1 & & & 3 & $12.00 \%$ \\
\hline 3 & $\begin{array}{c}\text { 명사를 수식하는 능동 } \\
\text { ·수동형 분사 }\end{array}$ & 1 & 1 & & & 1 & 3 & $12.00 \%$ \\
\hline 4 & 주어+동사 수일치 & & 1 & 1 & & 1 & 3 & $12.00 \%$ \\
\hline 5 & 관계대명사 & & & & 1 & 1 & 2 & $8.00 \%$ \\
\hline 6 & 수동태 & & 1 & & 1 & & 2 & $8.00 \%$ \\
\hline 7 & to부정사 & & & 1 & & & 1 & $4.00 \%$ \\
\hline 8 & 대동사 do & & & & 1 & & 1 & $4.00 \%$ \\
\hline 9 & 문장의 동사 & 1 & & & & & 1 & $4.00 \%$ \\
\hline 10 & 부사의 수식 & 1 & & & & & 1 & $4.00 \%$ \\
\hline 11 & 재귀대명사 & & & & & 1 & 1 & $4.00 \%$ \\
\hline 12 & 전치사의 목적어 & & & & 1 & & 1 & $4.00 \%$ \\
\hline 13 & 접속사 as & & & & & 1 & 1 & $4.00 \%$ \\
\hline 14 & 현재진행형 & & & 1 & & & 1 & $4.00 \%$ \\
\hline & 합 계 & 5 & 5 & 5 & 5 & 5 & 25 & 100 \\
\hline
\end{tabular}

출제된 문법 내용 중에서 인칭, 수일치, 후치수식 등의 내용을 포함한 대명사가 4회로 가장 많이 출제되었으며 전체 문법 내용의 $16 \%$ 의 비중을 차지했다. 명사절, 명사를 수식하는 능동 - 수동형 분사, 주어와 동사의 수 일치에 관한 문법 내용이 각각 3 회씩 출제되어 전체 문법 내용의 $12 \%$ 씩을 차지했다. 관계대명사와 수동태에 관한 지식을 묻는 문제는 각각 2회씩 출제되어 전체 문법 내용 의 $8 \%$ 를 차지하였다. 그밖에 1 번씩 출제된 문법 내용은 to 부정사, 대동사 do, 문장의 동사, 부 사의 수식, 재귀대명사, 전치사의 목적어, 접속사 as, 현재 진행형에 관한 내용으로 각각 $4 \%$ 의 비 율을 차지했다.

영어 I 교과서 10 종에서 2회 이상 제시된 문법 요소와 최근 5 년간 대학수학능력시험에 출제된 
문법 요소 14 가지 항목에 대한 상관관계를 분석한 결과 $\mathrm{r}=109, \mathrm{p}=$. 712 로 낮은 상관관계를 보였 지만 통계적으로 유의하지 않다. 역시 영어II 교과서 9종에서 2회 이상 제시된 문법요소와 대학수 학능력시험에 출제된 14 개의 문법 항목에 대한 상관관계에서도 $\mathrm{r}=-.044, \mathrm{p}=$. 880의 결과가 나옴으 로써 낮은 상관관계를 보여주지만, 이 역시 통계적으로는 유의하지 않다.

\section{5. 결론 및 제언}

본 연구에서는 2015 개정 고등학교 영어| 교과서 10종과 영어II 교과서 9종에서 제시한 언어형식에 표현된 문법 요소를 분석하였다. 또한 교과서의 문법요소들과 최근 5 년간 시행된 대학수학능력시 험 영어 어법 문항의 문법 요소 간의 상관관계를 분석하였다.

1) 검인정 교과서 간에 공통된 핵심 문법요소들은 영어 | 이 영어॥보다 더 많았고, 영어 II의 문 법요소들의 종류가 좀 더 다양하였다. 영어। 에서는 분사가 15회의 빈도수를 차지하며 한 교과서 내에서도 중복적으로 이를 핵심요소로 다루었다. 그에 반해 영어 II는 가장 많은 빈도수를 보인 문 법요소인 부사절이 9회에 그쳤고, 1 3회의 빈도수에 해당하는 요소들이 영어 |보다 많은 것으로 분석되었다. 이는 영어॥가 상대적으로 난이도가 있는 문법 요소를 다룸으로써 좀 더 세부적이고 교과서마다 다양한 문법요소를 채택한 것으로 해석될 수 있다.

2) 영어|과 영어II 교과서와 대학수학능력시험 어법 문항의 문법요소와 상관관계를 분석한 결 과 통계적으로 유의미하지는 않았지만 낮은 상관관계를 보였다. 그 이유로는 대학수학능력시험 내 어법 문항의 수가 너무 적어 다양한 문법요소들이 출제되는 것에는 한계가 있고 통계적으로도 표 본의 수가 적어 생기는 어려움 때문으로 추측된다. 하지만 단순 비교분석을 했을 때에도 부정사, 동명사, 가정법 등의 요소들은 교과서에서 다회 출현하였지만, 대학수학능력시험에서는 1 회 출제되 거나 혹은 전혀 출제되지 않았다. 또한 대학수학능력시험의 어법 문항 수가 적은 것에 비해 2 3개 의 특정 문법요소가 연달아 출제되는 경향이 있어 다양한 문법요소를 반영하지 못한 것으로 볼 수 있다. 또한 몇몇 보기는 고등학교 교육과정 이전에 학습되어야 할 문법 내용이라 새로운 교육과정 에 적용되기에 어려움이 있었다. 본 연구 결과를 비추어 볼 때 교과서와 대학수학능력시험의 어법 문항의 연관성은 매우 낮은 것으로 볼 수 있다. 이러한 현상은 앞서 언급했듯이 학생들이 교과서 의 필요성에 대한 의문을 가져 주요 학습 도구로써 그 기능을 상실하고 공교육에 대한 불신을 초 래할 수 있다. 신뢰를 바탕으로 하는 공교육을 만들기 위해서는 국가 교육과정을 토대로 만들어진 교과서와 입시의 최종 목표인 대학수학능력시험의 연관성에 대한 연구가 중요하며 꼭 필요하다.

따라서 고등학교 교과서 문법요소와 대학수학능력시험에 관련하여 다음과 같이 제언을 하고자 한다. 우선, 교과서 제작자들은 다양한 문법요소를 교육과정에 포함하고 대학수학능력시험의 어법 문항과 직접적으로 연관된 다양한 난이도의 학습 활동과 과제를 제시해야 할 것이다. 교육과정에 따른 교과서들이 체계적으로 다양한 문법요소를 반영하고 대학수학능력시험과 직접적으로 연관된 과제를 제시함으로써 학교 수업에서 교과서 활용의 효과성을 높일 수 있을 것이다. 또한 교사들은 
An Analysis Of Grammatical Items In High School English Textbooks And A Correlation Analysis Between English Textbooks And The Grammatical Test Items Of CSAT

교과서를 선정할 때 대학수학능력시험과 연계성을 고려하여 학습의 효율성과 수업 내 교과서의 활 용도를 높이고 학생들이 교과서에 대한 신뢰를 할 수 있게 해야 한다. 또한, 학습자와 교사들을 대 상으로 교과서와 대학수학능력시험 어법 문항의 연계성에 대한 인식에 대한 후속 연구가 이루어져 야 할 것이다. 문항을 비교·분석하는 것뿐만 아니라 교과서를 수업 현장에서 사용하는 학습자들과 교사들의 반응과 연계성에 대한 체감도를 조사한다면 더욱 의미 있는 연구가 될 것이다. 선행연구 [9]에서 이를 시도한 적이 있지만, 표본 수가 너무 적고 연구대상인 교과서 또한 한정적이라는 문 제가 있었다. 따라서 대학수학능력시험 출제 범위에 직접 해당이 되는 영어। 과 영어॥ 교과서의 문법요소를 분석한 것을 바탕으로 이를 사용하는 학생과 교사들을 대상으로 반응을 조사한다면 교 과서와 대학수학능력시험의 전반적인 연계성 연구에 큰 도움이 될 것이다.

마지막으로, 고등학교 영어 교과서 간의 문법요소 난이도에 대한 체계적인 제시가 필요하다. 2015 개정 교육과정에서 제시된 언어형식과 그 예문에서는 초·중·고 학교급만 표시되어있을 뿐 학 교급별 세부적인 난이도는 제시되어있지 않다. 본 연구 결과에서도 영어 | 과 영어॥ 교과서에 제 시되는 문법요소가 구분되지 않고 교과서마다 문법요소를 제시하는 순서가 각기 다른 것으로 나타 났다. 일반적으로 영어 I 교과서를 먼저 사용하고 영어 II 교과서를 심화 수업으로 진행하는 경우가 많기 때문에 고등학교 교육과정 내에서도 문법요소들을 난이도에 따라 제시할 수 있는 후속 연구 가 필요할 것으로 보인다.

\section{References}

[1] Jeong-ryeol Kim, Je-Young Lee, A Basic Study of English Immersion Lexicon for Math and Science, Asia-Pacific Journal of Educational Management Research, (2017), Vol.2, No.1, pp.135-140, DOI: http://dx.doi.org/10.21742/AJEMR.2017.2.1.22

[2] The curriculum of English Education (Notification No. 2015-74), Ministry of Education, (2015)

[3] Ji-Hye Lee, Mun-Koo Kang, An analysis of English Relative pronouns - focused on 'that', Asia-Pacific Journal of Educational Management Research, (2017), Vol.2, No.1, pp.123-128.

[4] Youn-A Kwon, Mun-Koo Kang, Analysis on grammar patterns of English textbooks for middle school juniors according to revised curriculum in 2009, Asia-Pacific Journal of Educational Management Research, (2016), Vol.1, No.1, pp.29-34, http://dx.doi.org/10.21742/AJEMR.2016.1.1.05

[5] Celce-Murcia M., Larsen-Freeman D., The Grammar Book, 3nd edition, Heinle ELT, (2015)

[6] In-Young Lee, Mun-Koo Kang, The Usage of English Articles according to Nouns, International Journal of Interactive Storytelling, (2017), Vol.2, No.1, pp.7-12.

[7] Long, M. H., Focus on form: A design feature in language teaching methodology, Jon Benjamins, (1991)

[8] Hyung-Joung Goo, Park Eun-Soo, A Comparative Analysis of the Grammar in High School Textbooks and in the CSAT, Journal of Research in Curriculum Instruction, (2013), Vol.17, No.1, pp.91-107, DOI: 
[9] Kim Jihae, Hae dong Kim, A Comparative Analysis of Grammatical Features between English Textbooks and College Scholastic Ability Test, The Journal of Modern British \& American Language \& Literature, (2015), Vol.33, No.3, pp.213-238, UCI: G704-000934.2015.33.3.004

[10] The Implementation Master Plan for College Scholastic Ability Test of 2020 School Year, Korea Institute for Curriculum and Evaluation, (2019)

[11] High School English I, Kyohaksa, (2017)

[12] High School English I, Kumsung Publishing Company, (2017)

[13] High School English I, Darakwon, (2017)

[14] High School English I, Dong-A publishing Company, (2017)

[15] High School English I, Visang Education Inc., (2017)

[16] High School English I, NE Neungyule, (2017)

[17] High School English I, YBM, (2017)

[18] High School English I, YBM Holdings, (2017)

[19] High School English I, Jihak Publishing Company, (2017)

[20] High School English I, Chunjae Education Inc., (2017)

[21] High School English П , Kumsung Publishing Company, (2017)

[22] High School English II, Darakwon, (2017)

[23] High School English II, Dong-A publishing Company, (2017)

[24] High School English II, Visang Education Inc., (2017)

[25] High School English II, NE Neungyule, (2017)

[26] High School English II, YBM, (2017)

[27] High School English II, YBM Holdings, (2017)

[28] High School English II, Jihak Publishing Company, (2017)

[29] High School English II, Chunjae Education Inc., (2017)

[30] Soo Young Chung, An Analysis of Grammar Items in the English Textbooks and Learners' Responses, The Graduate School of Education, Hankuk University of Foreign Studies, Master's thesis, (2017) 